\title{
The Allelopathic Potential of Hairy Vetch (Vicia villosa Roth.) Mulch
}

\author{
Charles M. Geddes, Andrea Cavalieri, Fouad Daayf, Robert H. Gulden \\ Department of Plant Science, University of Manitoba, Winnipeg, Canada \\ Email: Rob.Gulden@umanitoba.ca
}

Received 23 September 2015; accepted 24 October 2015; published 27 October 2015

Copyright (C) 2015 by authors and Scientific Research Publishing Inc.

This work is licensed under the Creative Commons Attribution International License (CC BY). http://creativecommons.org/licenses/by/4.0/

(c) (i) Open Access

\begin{abstract}
Hairy vetch (Vicia villosa Roth.) has been recognized as a good candidate for weed suppressive mulch in organic no-till cropping systems. In our study, the allelopathic potential of hairy vetch, fall rye (Secale cereale $\mathrm{L}$.) and winter wheat (Triticum aestivum L.) (extracted species) were evaluated at both vegetative and reproductive developmental stages (extract stage) based on the germination and radicle elongation of five response species using aqueous extracts in soil microcosms. Our study found hairy vetch shoot extract to have little allelopathic potential compared to fall rye or winter wheat, both species for which the allelopathic potential is well documented. Interestingly, hairy vetch was the only extracted species to increase in allelopathic suppression of radicle elongation at the reproductive stage when plant biomass is near maximum. This result was conceivably due to the increased concentration of the putative allelochemical cyanamide in reproductive tissue. Chemical inhibition of radicle elongation in this extract, however, was only observed in the domesticated response species wheat (Triticum aestivum L.) and canola (Brassica napus $\mathrm{L}$.). The allelopathic effect on germination varied and depended on extracted species, extract stage, and response species; whereas the effect on radicle elongation was similar among extracted species, yet unique within response species. This research demonstrated that allelopathy studies should include multiple allelopathic and response species to accurately quantify the magnitude of chemical effects among allelopathic species and to rule out potential phytotoxic chemical defense/detoxification mechanisms that exist in some response species.
\end{abstract}

\section{Keywords}

Cyanamide, Germination, Hormesis, Phytotoxin, Radicle Elongation

\section{Introduction}

Allelopathy is the chemical effect of one organism, plant or microbe, on another through the release of chemi-

How to cite this paper: Geddes, C.M., Cavalieri, A., Daayf, F. and Gulden, R.H. (2015) The Allelopathic Potential of Hairy Vetch (Vicia villosa Roth.) Mulch. American Journal of Plant Sciences, 6, 2651-2663. 
cals into the environment [1]. This effect is most commonly viewed as amensalism, where growth in one plant is inhibited while the other plant remains unaffected. However, allelopathy may also manifest as a neutral/positive (stimulatory) interaction in some situations [1]-[4]. This interaction has often been attributed to hormesis, defined as stimulatory effects on plant growth caused by subtoxic concentrations of allelopathic phytotoxins [4].

Hairy vetch, fall rye, and winter wheat have been utilized as cover crops or mulches for weed suppression in organic no-till agriculture because they allow for an extended window of biomass production in areas restricted to short growing seasons. In Manitoba, Canada, Halde et al. (2014) [5] recognized hairy vetch as a good mulch candidate because of high biomass production at the end of the mulch producing growing season $(9.1-10.7$ $\left.\mathrm{Mg} \cdot \mathrm{ha}^{-1}\right)$ and high biomass retention the following spring $\left(6.0-7.6 \mathrm{Mg} \cdot \mathrm{ha}^{-1}\right)$ into which subsequent crops could be planted. High mulch biomass combined with high weed control potential make hairy vetch an excellent candidate for weed suppressive mulch.

The differentiation between allelopathy and plant competition is difficult to address through field experimentation because it is challenging to isolate these forms of interference from one another due to lack of suitable control treatments [1] [6] [7]. A controlled laboratory microcosm approach can allow for isolation of the chemical effects of mulch residue, where aqueous extracts can be used to simulate allelochemical leachate. The inclusion of soil in allelopathic microcosms to account for microbial degradation and other interactions with soil is an important factor often overlooked in allelopathy studies [8] [9].

Wheat and rye have been recognized for the suppression of both germination and radicle elongation of several species via the release of benzoxazinoid allelochemicals. The main allelochemicals released by these species and their subsequent derivatives include 2,4-dihydroxy-1,4-benzoxazin-3-one (DIBOA), 2,4-dihydroxy-7-methoxy-1, 4-benzoxazin-3-one (DIMBOA), and 6-methoxybenzoxazolin-2-one (MBOA) as the main allelochemicals along with 2-hydroxy-7-methoxy-1,4-benzoxazin-3-one (HMBOA), 2-hydroxy-1,4-benzoxazin-3-one (HBOA), and benxoxazolin-2-one (BOA) in rye, and MBOA as the main allelochemical in wheat, along with HMBOA, and HBOA [1] [9]-[12].

Results from previous studies on the allelopathic potential of hairy vetch however, have been variable. In a greenhouse pot study, Inderjit and Asakawa, (2001) [13] determined that interference of hairy vetch with radish (Raphanus sativus L.) was not likely due to allelopathy, while Ercoli et al. (2005; 2007) [14] [15] attributed weed interference in both field and laboratory studies to phytotoxicity of hairy vetch. A series of greenhouse experiments using leached and unleached hairy vetch shoot tissue grown under field conditions suggested that allelopathy may play a role in weed suppression caused by hairy vetch mulch, but only within the first month after hairy vetch termination/mulch formation [16]. These studies, however, lacked osmotic controls and therefore were not clear as to whether emergence of the response species was due to allelopathic or osmotic effects. Inconsistent results surrounding the allelopathic potential of hairy vetch have created a need for further evaluation including effects on other weeds and crops and comparison of the observed effects to other previously documented allelopathic species.

Cyanamide, the putative allelochemical in hairy vetch, was originally thought to be solely a synthetic compound used as an agricultural fertilizer, and was not believed to be biosynthesized by plants [17]. Synthetic cyanamide has also been used as a fungicide, nematocide, herbicide [18], and to release bud and seed dormancy in several species [19]-[21]. The dimer form of cyanamide, dicyandiamide, also has been used as a nitrification inhibitor for agricultural production [22] [23]. In 1991, Maier-Greiner et al. [24] first isolated and characterized cyanamide hydratase, an enzyme uniquely responsible for the hydrolysis of cyanamide fertilizer into urea, from the soil borne fungus Myrothecium verrucaria (Alb. \& Schwein.) Ditmar. This discovery, spurred the question as to how an enzyme evolved to hydrolyze a synthetic compound that had only been synthesized since 1898 [17]. In 2003, Kamo et al. [25] discovered cyanamide as an allelochemical in hairy vetch which was the first report of cyanamide as a natural chemical bio-synthesized by plants.

The objectives of this study were to i) determine the allelopathic potential of hairy vetch by comparing it to fall rye and winter wheat throughout several response species; ii) separate the allelopathic from osmotic effects of the extracts evaluated; and iii) quantify the level of cyanamide in hairy vetch extracts. It was hypothesized that leachate from hairy vetch tissue would chemically suppress both germination and radicle elongation of the response species. It was also hypothesized that the allelopathic potential of hairy vetch would be greater than winter wheat, but less than fall rye based on germination and radicle elongation of the response species. Lastly, vegetative stage extracts were hypothesized to have greater allelopathic potential than reproductive stage extracts. 


\section{Materials and Methods}

Canola (cv. Sentry), wheat (cv. Waskada), kochia (Kochia scoparia L.), lamb’s quarters (Chenopodium album L.), and wild oat (Avena fatua L.) seeds (collectively the response species), agricultural crop and weed species common to the Canadian Prairies, were imbibed separately in aqueous extracts of vegetative and reproductive stage hairy vetch, fall rye, and winter wheat aboveground biomass. The germination medium was composed of 15 grams of unsterilized silty clay loam soil (Orthic Black Chernozem, Mollisol, 0 - 15 cm depth, 3.4\% OM, 7.1 pH, CEC $15.3 \mathrm{meq})$, collected from the Ian N. Morrison Research Station in Carman, MB, Canada (49 20'43.9"N, $\left.98^{\circ} 58^{\prime} 05.2^{\prime \prime} \mathrm{W}\right)$, and stored at $4^{\circ} \mathrm{C}$ prior to use. This soil medium was added to each petri dish (Fisher $100 \times 15$ $\mathrm{mm}$ ) microcosm along with 25 seeds of a specific response species. The microcosms were then irrigated with 6 milliliters of a specific extract, osmotic control, or distilled water $\left(\mathrm{di}_{2} \mathrm{O}\right)$. Following the introduction of an extract or control solution, each microcosm was placed in a growth room $\left(16: 8 \mathrm{hr}, 22: 18^{\circ} \mathrm{C}\right)$ in the dark for four to seven days. The experiment was a three-way factorial (extracted species $\times$ extract stage $\times$ response species) with controls, using a randomized complete block design with four blocks. Each of the four experimental blocks consisted of 45 treatments which included: six extract microcosms (three species $\times$ two stages), both hypertonic and hypotonic osmotic control microcosms, and a di $\mathrm{H}_{2} \mathrm{O}$ control microcosm for each of the five response species (nine treatments per response species). The experiment was also repeated using filter paper (Fisher brand, P8creped, $9 \mathrm{~cm}$ ) as a germination medium.

\subsection{Biomass and Response Species Collection}

Hairy vetch (cv. Unknown), fall rye (cv. Hazlet), and winter wheat (cv. Flourish) biomass, along with response species seed lots, were grown and collected at the Ian N. Morrison Research Station in Carman, Manitoba, Canada. A detailed description of the collection site can be found in Halde et al. (2014) [5]. Vegetative shoots of all extracted species were collected at the three-leaf stage (Zadok scale 13), while the reproductive shoots were collected immediately after flowering (Zadok scale 69). Biomass samples were air dried at room temperature, ground using a Wiley Mill ( $2 \mathrm{~mm}$ sieve), then stored at $4^{\circ} \mathrm{C}$ in air-tight bags for two weeks prior to extraction.

\subsection{Extract and Osmotic Control Preparation}

In an Erlenmeyer flask, dry ground biomass was submersed in di $\mathrm{H}_{2} \mathrm{O}(1: 10 \mathrm{wt} / \mathrm{wt}$, respectively; determined through preliminary experimentation [3]), then placed on an orbital shaker at $150 \mathrm{rpm}$ for 24 hours at $21^{\circ} \mathrm{C}$. The slurry was then filtered through two layers of cheesecloth and stored at $4{ }^{\circ} \mathrm{C}$ overnight. A Vapor Pressure Osmometer (5500 Vapor Pressure Osmometer, Wescor Inc., Logan, UT) was used to test the osmotic potential of all aqueous plant extracts. Mannitol $\left(\mathrm{C}_{6} \mathrm{H}_{14} \mathrm{O}_{6}\right)$ was added to di $\mathrm{H}_{2} \mathrm{O}$ to generate osmotic controls with the same osmotic potential as the highest $(-0.712 \mathrm{MPa}$, hereafter designated "hypotonic", least amount of solutes in solution) and lowest (-1.013 MPa, hereafter designated "hypertonic", greatest amount of solutes in solution) extracts. We only used two osmotic controls because of the narrow range of osmotic potentials among the plant extracts.

\subsection{High Performance Liquid Chromatography}

Reversed-phase high performance liquid chromatography (HPLC) was conducted using a Waters 2690 Separations Module, fitted with a LiChroCART® 4-4 LiChrospher® 100 RP-18 $5 \mu \mathrm{m}$ guard column and a LiChroCART® 250-4 LiChrospher® 100 RP-18 5 um separatory column, and equipped with a Waters 996 photodiode array detector to analyze the hairy vetch extracts following the methods of Wang et al. (2008) [26]. Briefly, extracts were centrifuged at $4696 \mathrm{~g}$ for 40 minutes at $4^{\circ} \mathrm{C}$ then filtered through a $0.2 \mu \mathrm{m}$ PTFE syringe filter (Thermo Scientific). A $50 \mu \mathrm{l}$ sample was injected and the column was eluted at a flow rate of $1 \mathrm{~mL} \cdot \mathrm{min}^{-1}$ with a mobile phase consisting of A) $0.1 \% \mathrm{H}_{3} \mathrm{PO}_{4}$ in water, and modified with B) HPLC grade acetonitrile using the following gradient: (time [min]/A [\%]/B [\%]) = 0/100/0, 5/95/5, 14/90/10, 0/80/20, 23/80/20, 30/65/35, 35/65/35, 43/50/50, 48/25/75, 55/0/100, 60/0/100. Cyanamide 99\% ( $\mathrm{NH}_{2} \mathrm{CN}$, Sigma-Aldrich) was used as an HPLC standard to identify this allelochemical in hairy vetch extracts. The peak specific to cyanamide was identified and quantified through extract spiking, UV absorbance spectra analyses, and the utilization of a concentration curve in ultrapure $\mathrm{H}_{2} \mathrm{O}$ with duplicate samples $\left(y=630.71 x ; R^{2}=0.9811\right.$; where: $y$ is peak height, and $x$ is concentration of cyanamide in $\mu \mathrm{g} \cdot \mathrm{ml}^{-1}$ ). The cyanamide standard solutions were prepared immediately prior to HPLC analysis to limit the formation of dicyandiamide [22]. 


\subsection{Quantification of Germination and Radicle Elongation}

Germination and radicle elongation quantification of canola, wheat, kochia, lamb's quarters, and wild oat microcosms were conducted after 4, 4, 5, 7, and 6 days after imbibition, respectively; due to species-specific time requirements to complete germination. After elutriation, seeds were considered germinated if the radicle had protruded through the seed coat. Average radicle length using three representative seedlings per microcosm were measured using ASSESS 2.0 Image Analysis Software [27].

\subsection{Data Preparation}

In our study, allelopathy was defined as the chemical effect (inhibition or stimulation) of a plant extract on a response species after accounting for the osmotic effect of the specific plant extract in question. The extract and osmotic effect on germination were corrected for dormancy and viability of response species using the di $\mathrm{H}_{2} \mathrm{O}$ control to calculate germination as a percent of that in di $\mathrm{H}_{2} \mathrm{O}$. The effect of the osmotic control (as a percent of the di $\mathrm{H}_{2} \mathrm{O}$ control) with the closest osmotic potential to that of the extract was then subtracted from the extract effect (as a percent of that in di $\mathrm{H}_{2} \mathrm{O}$ ). This resulted in the chemical effect on germination expressed as a percent change relative to the di $\mathrm{H}_{2} \mathrm{O}$ control (the "allelopathic effect"). In other words, data are presented as negative percentages indicating suppression and positive percentages indicating stimulation of response variables. Equation (1) was used to calculate the allelopathic effect on germination and radicle elongation within each experimental block:

$$
A=\left[\left(\frac{E}{W}\right) \times 100\right]-\left[\left(\frac{O}{W}\right) \times 100\right]
$$

where, $A$ = allelopathic effect on germination or radicle elongation, $E=$ number of germinated seedlings or average radicle length per seedling in a specific extract microcosm, $W=$ number of germinated seedlings or average radicle length per seedling in the corresponding di $\mathrm{H}_{2} \mathrm{O}$ control microcosm, and $O=$ number of germinated seedlings or average radicle length per seedling in the osmotic control microcosm with an osmotic potential most similar to that of the specific extract.

\subsection{Statistical Analyses}

Mixed model analysis in SAS 9.3 was used to conduct ANOVA on the allelopathic effect on germination and radicle elongation data as well as the osmotic effect on germination and radicle elongation [28]. The model for testing the allelopathic effect was a complete three-way factorial (extracted species $\times$ extract stage $\times$ response species) as the controls were used only to determine the allelopathic effect. To test osmotic effects, a two-way factorial (osmotic control $\times$ response species) model was used. The residuals were tested for normality, where Lund's test was used to remove outliers when necessary to meet the assumptions of ANOVA [29]. Extract stage, extracted species, and response species were considered fixed effects and experimental replication was considered a random effect. Treatment means were separated based on Fisher's protected LSD $(\alpha=0.05)$ using the pdmix 800 macro [30]. Least squares means $(\alpha=0.05)$ were used to determine significant differences between the allelopathic effect and corresponding osmotic effect for both germination and radicle elongation.

\section{Results}

\subsection{Filter Paper Microcosm Experiments}

A preliminary experiment conducted on filter paper in petri dish microcosms investigated the difference between shoot and root biomass using the same extracted species and response species as the current study (data not shown) [3]. Extracts were prepared using half the biomass compared to the present study, at a rate of 1:20 wt dry ground biomass/wt di $\mathrm{H}_{2} \mathrm{O}$. These extracts produced a range of allelopathic effects on germination from $-72.5 \%$ to $3.6 \%$ (lamb's quarters in winter wheat shoot extract and wild oat in hairy vetch root extract, respectively) and allelopathic effects on radicle elongation ranging from $-48.6 \%$ to $96.9 \%$ (wild oat in winter wheat shoot extract and lamb's quarters in fall rye shoot extract, respectively) relative to the di $\mathrm{H}_{2} \mathrm{O}$ control. This preliminary experiment also found that shoot biomass in all three extracted species consistently resulted in increased allelopathic inhibition of germination and radicle elongation ( $-43.6 \%$ and $-14.5 \%$, respectively) when 
compared to root biomass ( $-17.6 \%$ and $-5.3 \%$, respectively). Filter paper microcosms were also used in the present study. These microcosms were prepared using the more concentrated shoot biomass extracts from this study. In the present study, high concentrations of extracts in filter paper microcosms resulted in almost complete inhibition of germination in all treatments (data not shown); for this reason, only the allelopathic effect in soil microcosms data are reported.

\subsection{Allelopathic Effect on Germination}

Vegetative fall rye was the only extract to chemically suppress germination among all five response species and significant allelopathic effects on germination were only observed sporadically in all other extract and response species combinations. In vegetative fall rye, germination ranged from $-27.8 \%$ in lamb's quarters to $-106.8 \%$ in kochia relative to the di $\mathrm{H}_{2} \mathrm{O}$ control (Table 1). Vegetative hairy vetch and reproductive fall rye extracts, on the

Table 1. The allelopathic effect of vegetative and reproductive stage hairy vetch, fall rye and winter wheat shoot aqueous extracts on the germination of response species; expressed as a change in percent relative to the distilled water control.

\begin{tabular}{|c|c|c|c|c|c|}
\hline \multirow{2}{*}{$\begin{array}{c}\text { Developmental stage } \\
\text { Vegetative }\end{array}$} & \multirow{2}{*}{$\begin{array}{c}\text { Extracted species } \\
\text { Hairy vetch }\end{array}$} & \multirow{2}{*}{$\begin{array}{c}\text { Response species } \\
\text { Canola }\end{array}$} & \multicolumn{3}{|c|}{ Allelopathic effect on germination $\left(\Delta \% \text { relative to di } \mathrm{H}_{2} \mathrm{O}\right)^{\mathrm{a}, \mathrm{b}}$} \\
\hline & & & -17.6 & a-g & \\
\hline & & Wheat & -13.0 & b-e & \\
\hline & & Kochia & 0.0 & $\mathrm{ab}$ & \\
\hline & & Lamb’s quarters & 4.2 & $a-f$ & \\
\hline & & Wild oat & 10.3 & ac & \\
\hline & Fall rye & Canola & -55.0 & gh & $* *$ \\
\hline & & Wheat & -79.6 & hi & $* * *$ \\
\hline & & Kochia & -106.8 & $\mathrm{j}$ & $* * *$ \\
\hline & & Lamb’s quarters & -27.8 & $\mathrm{a}-\mathrm{g}$ & $* * *$ \\
\hline & & Wild oat & -35.3 & e-g & * \\
\hline & Winter wheat & Canola & -18.0 & $b-f$ & \\
\hline & & Wheat & -32.3 & d-g & \\
\hline & & Kochia & -89.2 & ij & $* * *$ \\
\hline & & Lamb's quarters & -47.9 & e-h & $* *$ \\
\hline & & Wild oat & 5.1 & $\mathrm{ab}$ & \\
\hline \multirow[t]{15}{*}{ Reproductive } & Hairy vetch & Canola & -21.9 & b-g & \\
\hline & & Wheat & -4.1 & $\mathrm{ab}$ & \\
\hline & & Kochia & -10.8 & a-e & \\
\hline & & Lamb's quarters & 13.9 & $\mathrm{ab}$ & $*$ \\
\hline & & Wild oat & 4.8 & $a b$ & \\
\hline & Fall rye & Canola & -3.3 & $\mathrm{a}-\mathrm{d}$ & \\
\hline & & Wheat & -7.1 & $a b$ & \\
\hline & & Kochia & 15.5 & $\mathrm{a}$ & \\
\hline & & Lamb’s quarters & -4.2 & $a-f$ & \\
\hline & & Wild oat & 4.8 & $a b$ & \\
\hline & Winter wheat & Canola & -23.3 & b-g & \\
\hline & & Wheat & -42.3 & fg & $*$ \\
\hline & & Kochia & -50.9 & gh & $* *$ \\
\hline & & Lamb’s quarters & -12.5 & a-g & \\
\hline & & Wild oat & -10.5 & a-e & \\
\hline
\end{tabular}

a) values in a column having the same letter(s) are not statistically different as determined by Fisher's protected $L S D(\alpha=0.05)$; b) negative values indicate suppression, whereas positive values indicate stimulation. ${ }^{*}, * *, * * *$ indicate significant differences between extract and corresponding osmotic control based on least squares means $(\alpha=0.05)$ at $\mathrm{P}<0.05, \mathrm{P}<0.01$, and $\mathrm{P}<0.0001$, respectively. 
other hand, did not have an allelopathic effect on germination of any response species (Table 1). Reproductive hairy vetch, which was at the stage of maximum biomass, considered ideal for the formation of mulch, did not chemically suppress germination of any of the response species. This extract, however, caused a $13.9 \%$ allelopathic stimulation of germination in lamb's quarters (Table 1). Winter wheat extracts inhibited germination in kochia and lamb's quarters to a greater extent at the vegetative than at the reproductive developmental stage. No allelopathic effect on germination of lamb's quarters was observed at the reproductive stage of winter wheat. In contrast, inhibition of wheat germination was greater at the reproductive than at the vegetative developmental stage of the winter wheat extract, where no allelopathic effect on wheat germination was observed at the latter stage. Germination in all other response species and extract combinations was not different from their respective osmotic controls.

\subsection{Allelopathic Effect on Radicle Elongation}

The allelopathic effect on radicle elongation (negative or positive) tended to be unique to each response species, irrespective of extracted species or developmental stage. In fact, although not always considered an allelopathic effect, radicle elongation was statistically the same in each response species among all extracted species. One exception was lamb's quarters, where a greater degree of stimulation was observed in fall rye extracts than the other extracted species (Table 2). The response-species-specific effects on radicle elongation may have been due to common chemical (inhibitory/stimulatory) constituents among all extracts, or potentially species-specific phytotoxin detoxification mechanisms. Interestingly, a stimulation of wild oat radicle elongation was also consistent among all extracted species (Table 2). For wild oat, however, this stimulation was not different from the effect of the osmotic control when exposed to hairy vetch and winter wheat extracts. Overall, allelopathic suppression of radicle elongation was observed in canola ( $-46.9 \%$ to $-57.7 \%)$, wheat ( $-24.6 \%$ to $-40.2 \%)$, and kochia $(-33.8 \%$ in winter wheat extracts only) with the greatest and most consistent suppression of radicle elongation observed in the domesticated response species (canola and wheat) (Table 2).

\subsection{Osmotic Effect on Germination and Radicle Elongation}

The range of osmotic potential among the extracts was relatively narrow and the osmotic controls within that range only affected germination in the weedy species, but not the domesticated species (crops). The hypotonic osmotic control, which was most similar to the osmotic potential of the reproductive hairy vetch, fall rye, and winter wheat extracts and the vegetative hairy vetch extract, only reduced germination in wild oat (31\% reduction compared to di $\mathrm{H}_{2} \mathrm{O}$ ) (Table 3). The hypertonic osmotic control, used for the vegetative fall rye and winter wheat extracts, suppressed germination of the small seeded species kochia (by about one-third from 52\% to 33\% total germination) and lamb’s quarters (by about half from 26\% to 13\% total germination) (Table 3).

Overall, radicle elongation was more sensitive to osmotic effects than germination. This was particularly obvious at the hypotonic osmotic potential where three species (wheat, lamb's quarters, and wild oat) showed

Table 2. The allelopathic effect of hairy vetch, fall rye, and winter wheat shoot aqueous extracts (throughout both vegetative and reproductive developmental stages) on radicle elongation of the response species; expressed as a change in percent relative to the distilled water control.

\begin{tabular}{|c|c|c|c|c|c|c|c|c|c|}
\hline \multirow{2}{*}{$\begin{array}{c}\text { Extracted species } \\
\text { Canola }\end{array}$} & \multicolumn{3}{|c|}{ Hairy vetch $^{\mathrm{a}, \mathrm{b}}$} & \multicolumn{3}{|c|}{ Fall rye $\mathrm{e}^{\mathrm{a}, \mathrm{b}}$} & \multicolumn{3}{|c|}{ Winter wheat ${ }^{\mathrm{a}, \mathrm{b}}$} \\
\hline & -57.6 & g & $* * *$ & -46.9 & fg & $* * *$ & -52.4 & fg & $* * *$ \\
\hline Wheat & -24.6 & de & $* *$ & -26.6 & de & $* *$ & -40.2 & e-g & $* *$ \\
\hline Kochia & -12.4 & $\mathrm{~d}$ & & -7.4 & $\mathrm{~cd}$ & & -33.8 & $d-f$ & $* *$ \\
\hline Lamb's quarters & 21.4 & $\mathrm{~b}$ & $* *$ & 62.5 & $\mathrm{a}$ & $* *$ & 26.3 & $\mathrm{~b}$ & $* *$ \\
\hline Wild oat & 9.1 & bc & & 16.1 & bc & $*$ & 10.5 & bc & \\
\hline
\end{tabular}

avalues in a column having the same letter(s) are not statistically different as determined by Fisher's protected LSD ( $\alpha=0.05)$; ${ }^{\mathrm{b}}$ negative values indicate suppression, whereas positive values indicate stimulation. ${ }^{*}, * *, * * *$ indicate significant differences between extract and corresponding osmotic control based on least squares means $(\alpha=0.05)$ at $\mathrm{P}<0.05, \mathrm{P}<0.01, \mathrm{P}<0.0001$, respectively. 
Table 3. The effect of osmotic controls on germination and radicle elongation of response species; expressed as total germination percentage and average radicle length per seedling.

\begin{tabular}{|c|c|c|c|c|c|c|}
\hline \multirow{2}{*}{$\begin{array}{c}\text { Osmotic control } \\
\text { di } \mathrm{H}_{2} \mathrm{O}^{\mathrm{b}}\end{array}$} & \multirow[t]{2}{*}{ Osmotic potential (MPa) } & \multirow{2}{*}{$\begin{array}{c}\text { Response species } \\
\text { Canola }\end{array}$} & \multicolumn{2}{|c|}{ Germination (\%) } & \multicolumn{2}{|c|}{ Radicle length (mm) } \\
\hline & & & 93.0 & a & 55.9 & de \\
\hline & & Wheat & 99.0 & $\mathrm{a}$ & 200.0 & a \\
\hline & & Kochia & 52.0 & c & 22.3 & $\mathrm{f}-\mathrm{h}$ \\
\hline & & Lamb’s quarters & 26.0 & de & 41.9 & d-f \\
\hline & & Wild oat & 88.0 & $a b$ & 143.8 & $\mathrm{~b}$ \\
\hline \multirow[t]{5}{*}{ Hypotonic $^{c}$} & -0.712 & Canola & 97.0 & a & 56.0 & d \\
\hline & & Wheat & 99.0 & a & 127.8 & $\mathrm{~b}$ \\
\hline & & Kochia & 56.0 & c & 18.1 & gh \\
\hline & & Lamb’s quarters & 19.0 & ef & 12.1 & $\mathrm{~h}$ \\
\hline & & Wild oat & 57.0 & c & 51.8 & de \\
\hline \multirow[t]{5}{*}{ Hypertonic $^{\mathrm{d}}$} & -1.013 & Canola & 95.0 & a & 44.3 & de \\
\hline & & Wheat & 99.0 & a & 89.3 & c \\
\hline & & Kochia & 33.0 & d & 9.6 & $\mathrm{~h}$ \\
\hline & & Lamb's quarters & 13.0 & $\mathrm{f}$ & 9.6 & h \\
\hline & & Wild oat & 76.0 & $\mathrm{~b}$ & 35.2 & e-g \\
\hline
\end{tabular}

a values in a column having the same letter(s) are not statistically different as determined by Fisher's protected LSD ( $\alpha=0.05)$; ${ }^{\text {in- }}$ dicates the control used to account for seed-lot dormancy and viability; 'indicates the osmotic control used for vegetative hairy vetch $(-0.792 \mathrm{MPa})$, and reproductive hairy vetch $(-0.792 \mathrm{MPa})$, fall rye $(-0.712 \mathrm{MPa})$, and winter wheat $(-0.841 \mathrm{MPa})$ extracts;

${ }^{d}$ indicates the osmotic control used for vegetative fall rye $(-1.013 \mathrm{MPa})$, and winter wheat $(-0.970 \mathrm{MPa})$ extracts.

altered radicle elongation compared to only one species (wild oat) with altered germination (Table 3). Differences between the hypertonic and hypotonic osmotic controls were relatively small among all response species, except in wheat, where radicle elongation was suppressed to a greater extent in the hypertonic (56\% reduction in radicle elongation) compared to the hypotonic osmotic control (36\% reduction in radicle elongation) four days after imbibition (Table 3). However, both of these osmotic controls significantly inhibited radicle elongation of wheat seedlings when compared to di $\mathrm{H}_{2} \mathrm{O}$ (200 mm per seedling). The extracts and osmotic controls used in this study spanned a relatively narrow range of osmotic potential ranging from -0.712 to $-1.013 \mathrm{MPa}$ (Table 3 ).

\subsection{High Performance Liquid Chromatography Analysis}

Cyanamide, the putative allelopathic compound biosynthesized by hairy vetch, was identified at a retention time of 2.62 minutes in the hairy vetch extracts (Figure 1). Peak height was used to calculate the concentration of cyanamide instead of area under the peak because of the overlap of peaks observed in the aqueous hairy vetch extracts. Cyanamide was present at concentrations of 2159 and $2630 \mu \mathrm{g} \cdot \mathrm{ml}^{-1}$ or 215.9 and $263.0 \mu \mathrm{g} \cdot \mathrm{g}^{-1} \mathrm{DM}$ tissue in the vegetative and reproductive stage hairy vetch extracts, respectively. The $22 \%$ increase in cyanamide in the reproductive tissue extract of hairy vetch was consistent with the overall reduction in radicle elongation among all response species caused by the chemical effect of the reproductive hairy vetch extract (Figure 2). We did not look for the presence of cyanamide in wheat or rye extracts because cyanamide had not been previously identified as an allelochemical in these species.

\section{Discussion}

Based on germination and radicle elongation of the response species tested, hairy vetch would not be considered a good candidate species for weed suppressive allelopathic mulch. Hairy vetch did not chemically inhibit germination of any response species, and, in fact, stimulated the germination of lamb's quarters under our conditions. Additionally, the only allelopathic suppression of radicle elongation observed was that of the domesticated response species tested (canola and wheat). These data suggest that the weed suppression observed by Halde et 


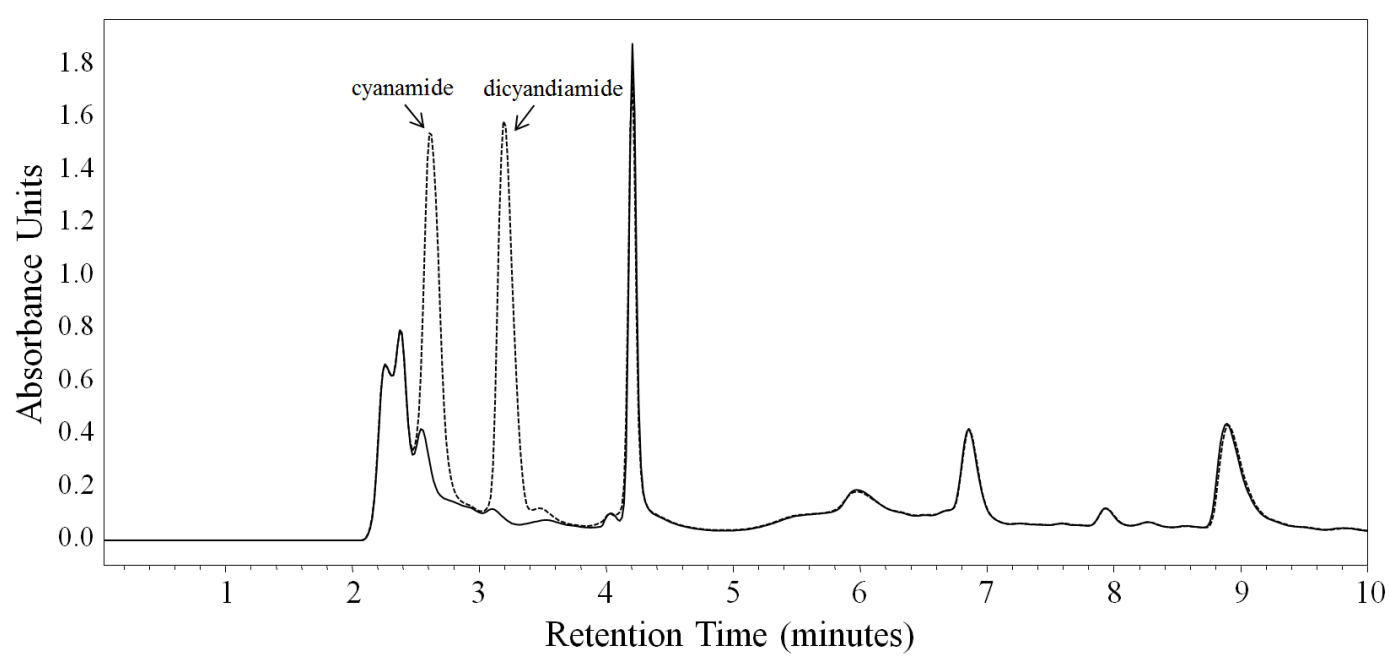

Figure 1. Chromatogram of UV absorbance (MaxPlot 200 to $400 \mathrm{~nm}$ ) for a 1:3 (v/v) solution of vegetative hairy vetch extract in a) ultrapure $\mathrm{H}_{2} \mathrm{O}$ (solid line), or b) $4000 \mu \mathrm{g} \cdot \mathrm{ml}^{-1}$ cyanamide solution (dotted line) during HPLC analysis. Cyanamide was identified at a retention time of 2.62 minutes with UV spectra matching that of the cyanamide standard.

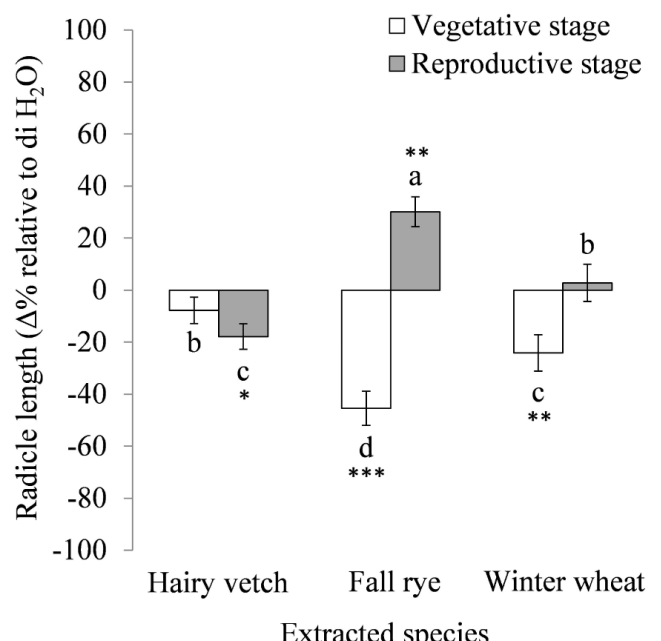

\begin{abstract}
Figure 2. The allelopathic effect of vegetative and reproductive stage shoot aqueous extracts of hairy vetch, fall rye, and winter wheat on radicle elongation throughout all response species tested (canola, wheat, kochia, lamb's quarters, and wild oat). Error bars indicate $+/-$ one standard error. Bars with the same letter are not statistically different as determined by Fisher's protected LSD $(\alpha=0.05)$. Significant differences between extracted species and corresponding osmotic controls based on least squares means $(\alpha=0.05)$ at $\mathrm{P}<0.05, \mathrm{P}<$ 0.01 , and $\mathrm{P}<0.0001$ are indicated by $* * *$, and $* * *$, respectively.
\end{abstract}

al. (2014) [5] was likely not due to allelopathy, but rather physical weed suppression as a result of high vetch biomass production. Therefore, in opposition to our proposed hypotheses, results from this study delineate hairy vetch as an undesirable candidate species for allelopathic mulch to control the weed species evaluated herein. It is important to note, however, that these data indicate the plausibility of hairy vetch as allelopathic mulch to inhibit volunteer wheat or canola in crop species other than those tested in our study.

Hairy vetch had less allelopathic potential than fall rye or winter wheat. This further suggests that weed interference caused by hairy vetch mulch is unlikely to be caused by allelopathy. However, this result opposes the majority of previous literature [1] [7] [14]-[16] [25]. In a field study, recruitment and biomass of redroot pigweed (Amaranthus retroflexus L.) and lamb's quarters were most suppressed by incorporated cover crops of hairy vetch when compared to brown mustard (Brassica juncea L.), rye, or bare soil [14]. A subsequent growth 
room study conducted using aqueous extracts in a filter paper petri dish assay, found that germination of redroot pigweed and common knotgrass (Polygonum aviculare L.) was not suppressed by hairy vetch extracts whereas germination of lamb's quarters was suppressed by about 20\% [15]. Differences between these laboratory and field studies were attributed to the phytotoxic effect of vetch biomass degradation and allelochemical interactions with soil biota [14] [15]. In our filter paper bioassay, germination of kochia and lamb's quarters was inhibited entirely by the aqueous extracts (data not shown) where more moderate effects were observed in the soil microcosm assay. This further suggests that allelochemical interactions in soil cause decreased allelopathic potential of leachate from plant biomass. Based on the amount of biomass needed to inhibit seedling emergence by 50\% (I50), Teasdale et al. (2007) [16] demonstrated decreased emergence of velvetleaf (Abutilon theophrasti Medic.), green foxtail (Setaria viridis L. Beauv.), and smooth pigweed (Amaranthus hybridus L.) under hairy vetch mulch one day before and five days after desiccation compared to one month after desiccation. This study determined that correlation of timing between hairy vetch desiccation/mulch formation and seeding of cash crop is imperative when attempting to utilize allelopathy for weed suppression [16]. It must be noted, however, that the absence of osmotic controls in this study did not allow the quantification of the true chemical effect of hairy vetch extracts and mulch leachate.

The putative allelochemical cyanamide was found in both vegetative and reproductive stage hairy vetch extracts at concentrations of 215.9 and $263.0 \mu \mathrm{gg} \cdot \mathrm{g}^{-1}$ dry weight (DW) tissue. Kamo et al. (2003) [25] first found cyanamide in hairy vetch at concentrations of 444,163 , and $89 \mu \mathrm{g} \cdot \mathrm{g}^{-1}$ fresh weight (FW) in shoot, endosperm, and root tissue of nine-day-old hairy vetch seedlings, respectively. A later publication reported cyanamide at concentrations of 369 to $498 \mu \mathrm{g} \cdot \mathrm{g}^{-1} \mathrm{FW}$ in the aboveground biomass of flowering hairy vetch [31]. These researchers also identified cyanamide in four-week-old hairy vetch at concentrations of 629, 256, and less than 20 $\mu \mathrm{g} \cdot \mathrm{g}^{-1} \mathrm{FW}$ in leaf, stem and root tissue, respectively [17]. Differences in chemical concentration between our study and those previously reported could either be due to the use of dried plant tissue, conditions during plant growth, and/or differences in extraction and quantification protocols [32]. For these reasons, a direct comparison of cyanamide concentrations cannot be made among the extracts in our study and those reported previously. It is also important to note that chemical constituents other than cyanamide were not identified in our HPLC analyses and therefore warrant further investigation. With that said, the aqueous extracts of dry tissue evaluated in our study would be reflective of the water soluble allelochemicals leached from dry hairy vetch mulch under conditions in the Northern Great Plains, where, shortly after the spring thaw, a cash crop would be seeded into dry vetch mulch from plants terminated near the end of the previous growing season. Additionally, environmental differences such as length of mulch overwintering, soil type and soil microbiota may also have an effect on allelochemical availability and degradation as well as the concomitant seedling responses to the aforementioned chemicals. Therefore, chemical concentrations alone may not be sufficient to accurately evaluate allelopathic potential in mulch-based systems.

Previous research found monocotyledonous species to be tolerant and dicotyledonous species to be sensitive to cyanamide phytotoxicity [33]. Using Pieper's value, a measure of the average time requirement for germination, Soltys et al. (2012) [33] found that $3.0 \mathrm{mM}$ cyanamide solution prolonged germination time of redroot pigweed, tomato (Solanum lycopersicum L.), lettuce (Lactuca sativa L.), and white mustard (Sinapsis alba L.), where germination timing of cleavers (Gallium aparine L.), corn (Zea mays L.), and wheat was unaffected. This effect was likely attributable to seed weight and thickness of the seed coat, where heavier seeds with thick seed coats generally required more time to germinate [33]. Although we did not measure the average time requirement for germination, this effect may have been observed in the differences among radicle elongation. Our study showed no apparent relationship between growth habit (monocotyledonous or dicotyledonous), seed size or allelopathic effects. In the absence of soil, cyanamide in solution has been shown to affect root growth of onion in a dose-dependent manner from $2-10 \mathrm{mM}$ [34]. This coincides with the greater inhibition of radicle elongation and increased cyanamide concentration observed between the vegetative $(51.36 \mathrm{mM})$ and reproductive $(62.56$ $\mathrm{mM}$ ) stage hairy vetch extracts in our study, which was well above the minimum biologically active concentrations required. However, the difference in cyanamide concentration between vegetative and reproductive stage extracts was small enough to indicate that there may be other chemical constituents involved in the observed allelopathic effects. Kamo et al. (2003) [25] showed that $0.24 \mathrm{mM} \mathrm{(100} \mathrm{ppm)} \mathrm{cyanamide} \mathrm{solution} \mathrm{inhibited} \mathrm{radicle}$ elongation of lettuce seedlings by $40 \%$ in a filter paper petri dish assay. This result, however, did not include the possible effect of cyanamide binding to the soil matrix and/or degradation by soil microbes. Due to the presence of soil in our microcosm assay, the concentration of cyanamide in our extracts would likely not be equal to the 
concentration being absorbed by the imbibed response species, making any concentration comparison difficult to interpret. However, it is important to consider the effect of allelochemical degradation in soil when comparing among multiple response species with inherently different time requirements to complete germination. Interestingly these data show an observable relationship between length of time from imbibition to microcosm evaluation and allelopathic effect. Canola and wheat, being the first species to germinate, showed the greatest response to allelopathy, whereas wild oat, being the last species to germinate, showed the mildest response to allelopathy overall. This observation indicates a possible relationship between allelopathic effect and allelochemical degradation by soil microorganisms.

The mechanism by which cyanamide alters germination or root elongation has yet to be determined. Cyanamide solution, in a petri-dish assay, decreased the quantity of mitotic cells, suppressed the propagation of meristematic cells, and altered the cytoskeleton arrangement in onion (Allium cepa L.) [34]. In a subsequent study on tomato, cyanamide inhibited root growth, likely due to altered cell division, an imbalance of the hormones ethylene and auxin, and differences in expansin gene expression [35]. To date, no research has been conducted on cyanamide mode of action using the species evaluated in this study.

Contrary to hairy vetch, vegetative stage fall rye and winter wheat had the greatest allelopathic effect on germination when compared to the corresponding reproductive stage extracts; likely related to higher hydroxamic acid concentration in vegetative tissue [36]. This shows potential for fall rye or winter wheat to be used as a cover crop incorporated at early growth stages for utilization of allelopathy for weed suppression. We did not evaluate known allelochemicals in fall rye or winter wheat because these putative benzoxazinoid allelochemicals and their derivatives are relatively unstable and not readily available aside from chemical synthesis [9] [12] [37]. Interestingly, reproductive stage fall rye had the greatest stimulatory effect on radicle elongation of response species; likely due to hormesis caused by the decrease of hydroxamic acids in fall rye tissue throughout its development [4] [9] [36]. Reproductive stage fall rye and winter wheat mulches expressed potential for utilization for species-specific growth promotion.

In our study, radicle elongation of both lamb's quarters and wild oat were allelopathically stimulated by all extracts, whereas radicle elongation in the other three response species was suppressed. Coincidentally, lamb’s quarters and wild oat also required the longest amount of time before germination could be evaluated. There is a possibility that the stimulation of radicle elongation observed could be due to allelochemical degradation in soil over time; however, differences in species-specific time required to complete germination can create difficulty when trying to correct for degradation of allelochemicals. In a growth room pot experiment, Krogh et al. (2006) [12] determined the maximum concentration of the allelochemical MBOA (154 ng $\mathrm{g}^{-1} \mathrm{DW}$ soil) in soil one day after the incorporation of wheat (one seedling in $300 \mathrm{~g}$ soil). Using first order degradation kinetics, they determined MBOA to have a $\mathrm{DT}_{50}$ (time required for the chemical to reach half of the maximum concentration) of 1.3 to 1.6 days in soil. The maximum amount of DIBOA (53 ng. $\mathrm{g}^{-1} \mathrm{DW}$ soil) in soil one day following incorporation of rye (one seedling in $300 \mathrm{~g}$ soil) was also determined [12]. The concentration of HBOA was found to increase as DIBOA and BOA degraded, reaching its maximum concentration $\left(\sim 100 \mathrm{ng} \cdot \mathrm{g}^{-1} \mathrm{DW}\right.$ soil) in soil four days after the incorporation of rye [12]. Lamb’s quarters seedlings have been noted to have a strong detoxification mechanism against benzoxazinoid allelochemicals [9]. In a greenhouse tray experiment, leachate from hairy vetch mulch had a stimulatory effect on the emergence of lamb’s quarters seedlings [16]. Additionally, root elongation of lamb’s quarters seedlings increased (approximately 120\% to 135\% of the deionized water control) when imbibed with aqueous extracts of hairy vetch in a filter paper assay [16]. This shows the possibility of allelopathy for species-specific growth promotion.

Radicle elongation seemed to be more sensitive to the osmotic component than the allelopathic component of the plant extracts. Nevertheless, after accounting for the osmotic effect of extracts in this study, radicle elongation still remained a more sensitive measure of allelopathic potential than germination. Although the range of osmotic potential among extracts was relatively narrow, the observed osmotic potentials were hypertonic enough to affect the rate of water uptake by seed [38]. Our study showed that it is imperative to include osmotic controls to account for osmotic potential of extracts in allelopathy studies. Al-Kahari, (1998) [38] found germination and radicle elongation of wheat, after eleven days, to be greatly affected when germinated in 0 to -1.4 MPa solutions of polyethylene glycol 8000, where a decrease in germination (99\% to 7\%) and root length (15 $\mathrm{cm}$ to $0.2 \mathrm{~cm}$ ) was correlated with an increase in solute concentration. In another study, time to reach $10 \%$ germination of wheat increased from $44 \mathrm{~h}$ to $124.7 \mathrm{~h}$ when germinated in $\mathrm{NaCl}, \mathrm{Na}_{2} \mathrm{SO}_{4}, \mathrm{KCl}_{2} \mathrm{~K}_{2} \mathrm{SO}_{4}, \mathrm{MgCl}_{2}$, $\mathrm{MgSO}_{4}$, or polyethylene glycol 8000 solutions ranging from $-0.3 \mathrm{MPa}$ to $-1.8 \mathrm{MPa}$ [39]. However, in our study 
total germination of wheat was not affected by the osmotic controls at -0.712 and $-1.013 \mathrm{MPa}$. Radicle elongation of wheat, on the other hand, was greatly inhibited in both the hypotonic $(127.8 \mathrm{~mm})$ and hypertonic (89.3 $\mathrm{mm})$ osmotic controls when compared to di $\mathrm{H}_{2} \mathrm{O}(200.0 \mathrm{~mm})$. Boyd et al. (2004) [40] found that the germination percentage of canola ( $84 \%, 42 \%$, and $15 \%$ ), wheat ( $83 \%, 69 \%$, and $40 \%$ ), and wild oat $(42 \%, 11 \%$, and $1 \%$ ) decreased with increasing solute concentration in $-0.01,-0.5$, and -1.00 MPa polyethylene glycol 6000 solutions, respectively. Differences in response species germination between our study and that of Boyd et al. (2004) [40] could be due to the presence of soil as a germination medium in our microcosm assay. Many allelopathy assays use germination and radicle elongation as response variables to assess allelopathic potential. However, evaluation of the allelopathic effect on radicle elongation has been shown to be a more sensitive measure than germination [1] [15]. It is possible that the response observed as radicle elongation could be due to an extract induced delay in the time to germination; therefore explaining the sensitivity of the radicle elongation response variable in allelopathy studies.

\section{Conclusion}

In summary, hairy vetch was determined to be an impractical candidate species for allelopathic mulch based on germination and radicle elongation of the response species in this study. Overall, the allelopathic effect on radicle elongation was more dependent on response species than extracted species. Results from this study suggest that allelopathic effects on radicle elongation are more dependent on the physiological characteristics and detoxification mechanisms of response species rather than the chemical effect of different extracted species. These data indicate that allelopathy studies should not only evaluate one allelopathic species but compare between more than one allelopathic species to determine whether observed effects are caused by the allelochemicals in question or are simply a result of species-specific defense/detoxification mechanisms of several phytotoxic allelochemicals as observed with wild oat and lamb's quarters in this study. Further research should focus on cyanamide degradation in soil, as well as the mode of action of cyanamide on the response species evaluated in this study. Future research should also focus on the stimulation of radicle elongation observed in wild oat and lamb's quarters. This shows the possibility for utilization of allelopathy for species-specific growth promotion. Additionally, agroecologists should focus on the deliberate incorporation of allelopathic interactions in a comprehensive integrated weed management approach. This strategy may help further delay the evolution of herbicide resistance in current conventional cropping systems.

\section{Acknowledgements}

We would like to thank the Natural Sciences and Engineering Research Council of Canada for an Industrial Postgraduate Scholarship to CMG and a Discovery Grant to RHG. We would also like to thank Lorne Adam for technical assistance.

\section{References}

[1] Rice, E.L. (1984) Allelopathy. Physiological Ecology: A Series of Monographs, Texts, and Treaties. 2nd Edition, Academic Press Inc., Orlando.

[2] Geddes, C.M., Cavalieri, A., Daayf, F. and Gulden, R.H. (2013) The Allelopathic Potential of Hairy Vetch, Fall Rye and Winter Wheat in a Silty Clay Loam Soil. Poster Presentation. CSSS/MAC/ASA, CSSA, and SSSA. Tampa. https://scisoc.confex.com/crops/2013am/webprogram/Paper80586.html

[3] Geddes, C.M., Cavalieri, A. and Gulden, R.H. (2012) The Allelopathic Potential of Hairy Vetch, Fall Rye and Winter Wheat. CWSS/MAC. Poster Presentation. http://umanitoba.ca/faculties/afs/agronomists_conf/media/2013_Geddes-Gulden_Allelopathic_SA2013.pdf

[4] Belz, R.G., Edivaldo, D.V. and Duke, S.O. (2007) Dose/Response Relationships in Allelopathy Research. In: Fujii, Y. and Parvez, M.M., Eds., Allelopathy: Concepts and Methodology, Science Publishers, Enfield, 4-29.

[5] Halde, C., Gulden, G.H. and Entz, M.H. (2014) Selecting Cover Crop Mulches for Organic Rotational No-Till Systems in Manitoba, Canada. Agronomy Journal, 106, 1193-1204. http://dx.doi.org/10.2134/agronj13.0402

[6] Blum, U. (2007) Can Data Derived from Field and Laboratory Bioassays Establish the Existence of Allelopathic Interactions in Nature? In: Fujii, Y. and Parvez, M.M., Eds., Allelopathy: Concepts and Methodology, Science Publishers, Enfield, 31-38.

[7] Fujii, Y. (2001) Screening and Future Exploitation of Allelopathic Plants as Alternative Herbicides with Special Ref- 
erence to Hairy Vetch. Journal of Crop Production, 4, 257-275. http://dx.doi.org/10.1300/J144v04n02_09

[8] Inderjit (2005) Soil Microorganisms: An Important Determinant of Allelopathic Activity. Plant and Soil, 274, $227-236$. http://dx.doi.org/10.1007/s11104-004-0159-x

[9] Schulz, M., Marocco, A., Tabaglio, C., Macias, F.A. and Molinillo, J.M.G. (2013) Benzoxazinoids in Rye Allelopathy-From Discovery to Application in Sustainable Weed Control and Organic Farming. Journal of Chemical Ecology, 38, 154-174. http://dx.doi.org/10.1007/s10886-013-0235-x

[10] Burgos, N.R., Talbert, R.E., Kim, K.S. and Kuk, Y.I. (2004) Growth Inhibition and Root Ultrastructure of Cucumber Seedlings Exposed to Allelochemicals from Rye (Secale cereale). Journal of Chemical Ecology, 30, 671-689. http://dx.doi.org/10.1023/B:JOEC.0000018637.94002.ba

[11] Copaja, S.V., Villarroel, E., Bravo, H.R., Pizarro, L. and Argandona, V.H. (2006) Hydroxamic Acids in Secale cereale L. and The Relationship with Their Antifeedant and Allelopathic Properties. Verlag der Zeitschriftfür Naturforschung, 61, 670-676. http://dx.doi.org/10.1515/znc-2006-9-1010

[12] Krogh, S.S., Mensz, S.J.M., Nielsen, S.T., Mortensen, A.G., Christophersen, C. and Fomsgaard, I.S. (2006) Fate of Benzoxazinone Allelochemicals in Soil after Incorporation of Wheat and Rye Sprouts. Journal of Agricultural and Food Chemistry, 54, 1064-1074. http://dx.doi.org/10.1021/jf051147i

[13] Inderjit and Asakawa, C. (2001) Nature of Interference Potential of Hairy Vetch (Vicia villosa Roth) to Radish (Raphanus sativus L.) Does Allelopathy Play Any Role? Crop Protection, 20, 261-265. http://dx.doi.org/10.1016/S0261-2194(00)00136-8

[14] Ercoli, L., Masoni, A. and Pampana, S. (2005) Short Communication: Weed Suppression by Winter Cover Crops. Allelopathy Journal, 16, 273-278.

[15] Ercoli, L., Masoni, A., Pampana, S. and Arduini, I. (2007) Allelopathic Effects of Rye, Brown Mustard and Hairy Vetch on Redroot Pigweed, Common Lambsquarter and Knotweed. Allelopathy Journal, 19, 249-256.

[16] Teasdale, J.R., Abdul-Baki, A.A., Park, Y.B. and Rosecrance, R.C. (2007) The Potential for Allelopathy during Decomposition of Hairy Vetch Residue. In: Fujii, Y. and Parvex, M.M., Eds., Allelopathy: Concepts and Methodology, Science Publishers, Enfield, 211-225.

[17] Kamo, T., Endo, M., Sato, M., Kasahara, R., Yamaya, H., Hiradate, S., Fujii, Y., Hirai, N. and Hirota, M. (2008) Limited Distribution of Natural Cyanamide in Higher Plants: Occurrence in Vicia villosa Subsp. varia, V. cracca, and Robinia pseudo-acacia. Phytochemistry, 69, 1166-1172. http://dx.doi.org/10.1016/j.phytochem.2007.11.004

[18] Kamo, T., Kato, K., Hiradate, S., Nakajima, E., Fujii, Y. and Hirota, M. (2006) Evidence of Cyanamide Production in Hairy Vetch Vicia villosa. Natural Product Research, 20, 429-433. http://dx.doi.org/10.1080/14786410500143583

[19] Guevara, E., Jimenez, V.M., Herrera, J. and Bangerth, F. (2008) Effect of Hydrogen Cyanamide on the Endogenous Hormonal Content of Pea Seedlings (Pisum sativum L.). Brazilian Journal of Plant Physiology, 20, 159-163. http://dx.doi.org/10.1590/S1677-04202008000200008

[20] Jackson, J.E. and Bepete, M. (1995) The Effect of Hydrogen Cyanamide (Dormex) on Flowering and Cropping of Different Apple Cultivars under Tropical Conditions of Sub-Optimal Winter Chilling. Scientia Horticulturae, 60, 293-304. http://dx.doi.org/10.1016/0304-4238(94)00707-M

[21] Or, E., Vilozny, I., Fennel, A., Eyal, Y. and Ogrodovitch, A. (2002) Dormancy in Grape Buds: Isolation and Characterization of Catalase cDNA and Analysis of Its Expression Following Chemical Induction of Bud Dormancy Release. Plant Science, 162, 121-130. http://dx.doi.org/10.1016/S0168-9452(01)00542-8

[22] Turowski, M. and Deshmukh, B. (2004) Direct Chromatographic Method for Determination of Hydrogen Cyanamide and Dicyandiamide in Aqueous Solutions. Analytical Letters, 37, 1981-1989. http://dx.doi.org/10.1081/AL-120039440

[23] Willison, W. and Anderson, J.M. (1991) Dicyandiamide as an Inhibitor of Denitrification in Coniferous Forest Soils. Soil Biology \& Biochemistry, 23, 605-607. http://dx.doi.org/10.1016/0038-0717(91)90071-Q

[24] Maier-Greiner, E.H., Obermaier-Skrobranek, B.M.M., Estermaier, L.M., Kammerloher, W., Freund, C., Wulfing, C., Burkert, U.I., Matern, D.H., Breuer, M., Eulitz, M., Kufrevioglu, O.I. and Hartmann, G.R. (1991) Isolation and Properties of a Nitrile Hydratase from the Soil Fungus Myrothecium verrucaria That Is Highly Specific for the Fertilizer Cyanamide and Cloning of Its Gene. Proceedings of the Natural Academy of Sciences of the United States of America, 88, 4260-4264. http://dx.doi.org/10.1073/pnas.88.10.4260

[25] Kamo, T., Hiradate, S. and Fujii, Y. (2003) First Isolation of Natural Cyanamide as a Possible Allelochemical from Hairy Vetch. Journal of Chemical Ecology, 29, 275-283. http://dx.doi.org/10.1023/A:1022621709486

[26] Wang, X., Hadrami, E.I., Adam, L.R. and Daayf, F. (2008) Differential Activation and Suppression of Potato Defence Responses by Phytophthora infestans Isolates Representing US-1 and US-8 Genotypes. Plant Pathology, 57, 10261037. http://dx.doi.org/10.1111/j.1365-3059.2008.01866.x

[27] Lamari, L. (2008) ASSESS 2.0 Image Analysis Software for Plant Disease Quantification. American Phytopathologi- 
cal Society, St. Paul.

[28] Littell, R.C., Miliken, G.A., Stroup, W.W. and Wolfinger, R.D. (1996) SAS System for Mixed Models. SAS Institute, Cary, 633.

[29] Lund, R.E. (1975) Tables for an Approximate Test for Outliers in Linear Models. Technometrics, 17, 473-476. http://dx.doi.org/10.1080/00401706.1975.10489374

[30] Saxton, A. (1998) A Macro for Converting Mean Separation Output to Letter Groupings in Proc Mixed. In: Proceedings of the 23rd SAS Users Group International, SAS Institute, Cary, 1243-1246.

[31] Kamo, T., Sato, M., Kato, K., Hiradate, S., Nakajima, E., Fujii, Y. and Hirota, M. (2006) Quantification of Cyanamide Contents in Herbaceous Plants. Bioscience, Biotechnology, and Biochemistry, 70, 2310-2312. http://dx.doi.org/10.1271/bbb.60171

[32] Hiradate, S., Kamo, T., Nakajima, E., Kato, K. and Fujii, Y. (2005) Direct Quantitative Determination of Cyanamide by Stable Isotope Dilution Gas Chromatography-Mass Spectrometry. Journal of Chromatography A, 1098, 138-143. http://dx.doi.org/10.1016/j.chroma.2005.08.035

[33] Soltys, D., Bogatek, R. and Gniazdowska, A. (2012) Phytotoxic Effects of Cyanamide on Seed Germination and Seedling Growth of Weed and Crop Species. Acta Biologica Cracoviensia Series Botanica, 54, 87-92. http://dx.doi.org/10.2478/v10182-012-0025-8

[34] Soltys, D., Rudzinska-Langwald, A., Kurek, W., Gniazdowska, A., Sliwinska, E. and Bogatek, R. (2011) Cyanamide Mode of Action during Inhibition of Onion (Allium cepa L.) Root Growth Involves Disturbances in Cell Division and Cytoskeleton Formation. Planta, 234, 609-621. http://dx.doi.org/10.1007/s00425-011-1429-5

[35] Soltys, D., Rudzinska-Langwald, A., Gniazdowska, A., Wisniewska, A. and Bogatek, R. (2012) Inhibition of Tomato (Solanum lycopersicum L.) Root Growth by Cyanamide Is Due to Altered Cell Division, Phytohormone Balance and Expansin Gene Expression. Planta, 236, 1629-1638. http://dx.doi.org/10.1007/s00425-012-1722-y

[36] Rice, C.P., Park, Y.B., Adam, F., Abdul-Baki, A.A. and Teasdale, J.R. (2005) Hydroxamic Acid Content and Toxicity of Rye at Selected Growth Stages. Journal of Chemical Ecology, 31, 1887-1905. http://dx.doi.org/10.1007/s10886-005-5933-6

[37] Villagrasa, M., Eljarrat, E. and Barcelo, D. (2009) Analysis of Benzoxazinone Derivatives in Plant Tissues and Their Degradation Products in Agricultural Soils. Trends Analytical Chemistry, 28, 1103-1114. http://dx.doi.org/10.1016/j.trac.2009.07.001

[38] Al-Karaki, G.N. (1998) Response of Wheat and Barley during Germination to Seed Osmopriming at Different Water Potential. Journal of Agronomy and Crop Science, 181, 229-235. http://dx.doi.org/10.1111/j.1439-037X.1998.tb00422.x

[39] Hampson, C.R. and Simpson, G.M. (1989) Effect of Temperature, Salt, and Osmotic Potential on Early Growth of Wheat (Triticum aestivum). I. Germination. Canadian Journal of Botany, 68, 524-528. http://dx.doi.org/10.1139/b90-072

[40] Boyd, N. and Van Acker, R. (2004) Seed Germination of Common Weed Species as Affected by Oxygen Concentration, Light, and Osmotic Potential. Weed Science, 52, 589-596. http://dx.doi.org/10.1614/WS-03-15R2 